$1-1-2012$

\title{
Nitric Oxide Synthase Encapsulation in Liposomes: A Potential Delivery Platform to (Nitric Oxide)-Deficient Targets
}

\author{
Reshani H. Perera \\ Cleveland State University \\ Pubudu M. Peiris \\ Cleveland State University \\ Serban F. Peteu \\ Cleveland State University \\ Mekki Bayachou \\ Cleveland State University, M.BAYACHOU@csuohio.edu \\ Follow this and additional works at: https://engagedscholarship.csuohio.edu/scichem_facpub \\ Part of the Chemistry Commons \\ How does access to this work benefit you? Let us know!

\section{Publisher's Statement} \\ This is the accepted version of the following article: Perera, R. H.; Peiris, P. M.; Peteu, S. F.; \\ Bayachou, M. Nitric Oxide Synthase Encapsulation in Liposomes: a Potential Delivery Platform \\ to (Nitric Oxide)-Deficient Targets. Electroanalysis 2012, 24, 37-41., which has been published in \\ final form at http://onlinelibrary.wiley.com/doi/10.1002/elan.201100492/abstract
}

\section{Recommended Citation}

Perera, Reshani H.; Peiris, Pubudu M.; Peteu, Serban F.; and Bayachou, Mekki, "Nitric Oxide Synthase Encapsulation in Liposomes: A Potential Delivery Platform to (Nitric Oxide)-Deficient Targets" (2012). Chemistry Faculty Publications. 320.

https://engagedscholarship.csuohio.edu/scichem_facpub/320

This Article is brought to you for free and open access by the Chemistry Department at EngagedScholarship@CSU. It has been accepted for inclusion in Chemistry Faculty Publications by an authorized administrator of EngagedScholarship@CSU. For more information, please contact library.es@csuohio.edu. 


\title{
Nitric Oxide Synthase Encapsulation in Liposomes: a Potential Delivery Platform to (Nitric Oxide)-Deficient Targets
}

\author{
Reshani H. Perera, Pubudu M. Peiris, Serban F. Peteu, Mekki Bayachou
}

\begin{abstract}
Nitric oxide (NO) is a freely diffusible, gaseous free radical, associated with many physiological and pathological processes: such as neuronal signaling, immune response and inflammatory response. In mammalian organisms, NO is produced from $\mathrm{L}$ arginine in an NADPH dependent reaction catalyzed by a family of nitric oxide synthase (NOS) enzymes. Typically, large NO fluctuations in biological systems under/over a critical limit is associated with problems that range from transient dysfunctions to severe chronic disease states. In this regard, we explore the development of a potential delivery and release method of nitric oxide to NO deficient sites using liposomes as vehicles. Lipo somes have already been used as effective nano carriers. In this short communication, we report on the preparation and characterization of liposomes carrying a recombinant NOS enzyme. We report on the efficacy of using lipo somes to carry NOS enzymes, and on the extent of preservation of native NOS structure and function. In addition to the characterization of liposome stability and recovery of enzymatic activity after encapsulation in liposomes, we also measured the NO production upon NOS stimulation. The NO release was monitored with a nitric oxide ultra sensitive electrochemical microsensor placed near NOS carrying liposomes. This method of NOS carrying liposomes shows the promise of potential development as a platform for targeted NO delivery.
\end{abstract}

Keywords: Nitric oxide synthase, NOS loaded liposome, Nitric oxide, NO sensitive microsensor

After being recognized, 20 years ago, as the endotheliumderived relaxing factor in the vascular system [1], nitric oxide (NO) has been subsequently identified as a neurotransmitter, neuro-modulator [2] and a cytotoxic factor in the immune system [3,4]. Moreover, a number of studies have revealed a role for $\mathrm{NO}$ in producing tissue damage, such as ischemia/reperfusion injury [3,5] or excitatory neuronal death [6-8].

$\mathrm{NO}$ is produced from the guanidino group of L-arginine in an NADPH-dependent reaction, catalyzed by a family of nitric oxide synthase (NOS) enzymes [9]. Given NO involvement in numerous vital processes, a critical change in its physiological concentration can harm biological systems. For instance, lower than normal NO levels could lead to hypertension $[10,11]$, impotence $[12,13]$, hyperglycemia, and arteriosclerosis $[14,15]$, to cite a few.

However, a direct release of NO doses to biological targets has clinical limitations, due to both its relative short lifetime and high reactivity [16]. In this regard, in situ transport and delivery of NO-releasing sources such as NO-making enzymes (NOSs) represent potential alternatives. In a related aspect, the NOS gene transfer has been already reported as a potential approach to counteract NO deficiency [16-18]. Even though the NOS gene thera- py has some therapeutic benefits, there are several obstacles to advance clinical practice. The foremost concerns of NOS gene therapy are the limitations of currently available vectors, the need of targeted delivery methods, and the relative difficulties to control the in situ NOS expression.

By contrast, the targeted delivery of NOS enzymes is an important approach to explore. In this regard, carrying vectors such as liposomes are effective delivery systems, able to shuttle molecules to sites of action. Once at a cell site, the liposome lipid bilayer can fuse with the cell membrane bilayer, thereby releasing its contents. The advantages of using liposomes carrying target proteins include the stabilization, prevention of denaturation, or proteolysis of the protein. Consequently, the liposome-entrapped NOS could be safely ferried and released to preordered sites that can potentially be targeted using chemical groups on the surface of the liposomes.

One aim of this study is to investigate the effectiveness of the NOS liposomal transport, and to evaluate the protection of NOS native structure and function within the liposomal microenvironment for potential NO delivery to medically significant targets. Issues of targeted delivery to 
NO-deficient biological targets is not part of the current study.

Liposomes with encapsulated NOS enzymes. We prepared NOS-loaded liposomes using the lipid film hydration method, but in the presence of NOS enzymes. We used a 5:1 molar ratio of 1,2-distearoyl-glycero-3-phosphocholine (DSPC) to cholesterol. The thin film obtained is hydrated with an aqueous solution of the iNOS enzyme as described in the experimental section. The vesicle suspension obtained is then diluted with a $\mathrm{pH} 7.4$ buffer solution to the desired concentration.

Size characterization and size stability of NOS-loaded liposomes. We first measured the size distribution of the vesicles using dynamic light scattering (DLS). Like any suspension of particles, the Brownian motion of liposomes influences the scattering of laser light that is a measure of the diffusion coefficient, which can be used to calculate the diameter of liposomes. In our method, we use sequential extrusions through polycarbonate filter membranes with the desired pore size, which yields homogeneous size distribution of vesicle suspension. In a typical preparation, as described in the experimental section, the DLS analysis immediately after preparation, shows a mean vesicle size of about $110 \pm 30 \mathrm{~nm}$. The samples prepared with this method are relatively monodisperse as shown in a Figure 1A (polydispersity index is less than 0.1).

We then monitored the size of NOS-carrying liposomes as a function of time to assess their stability.

The dispersion of NOS-loaded liposomes was stored at $4{ }^{\circ} \mathrm{C}$ and was subjected to intermittent DLS analysis to measure any size change. Figure $1 \mathrm{~B}$ shows the change of the liposomal diameter as a function of time. The figure shows that the preparation maintains its characteristic diameter for the first 15 days. After this window of size stability, an onset of aggregation is observed, which leads to size increase noticed as early as 20 days. The liposome size significantly increases after 30 days. In fact, basic test of significance on the data used in Figure 1B shows that the average liposome diameter is $\sim 111 \mathrm{~nm}(N=5)$ for day 1 through day 20; the average diameter increases to about $144 \mathrm{~nm}(N=7)$ for days 23 through 45 . A basic $t$ test shows that the two averages are significantly different beyond the $95 \%$ confidence level. Close analysis of our samples show that the liposomes tend to fuse and aggregate, as a function of storage time at $4{ }^{\circ} \mathrm{C}$. At the point of 30 days, the vesicle dispersion was heterogeneous with an increasing polydispersity index higher than 1.0 , suggesting the formation of even larger vesicles as the result of aggregation.

NOS encapsulation efficiency. For liposomes to be used as a feasible delivery system, one needs to also consider the encapsulation efficiency or the loading capacity of the target protein (NOS in this case).

The encapsulation efficiency (\%) is defined as the ratio of the total NOS encapsulated in the liposome as compared to the total initial NOS input amount [19].
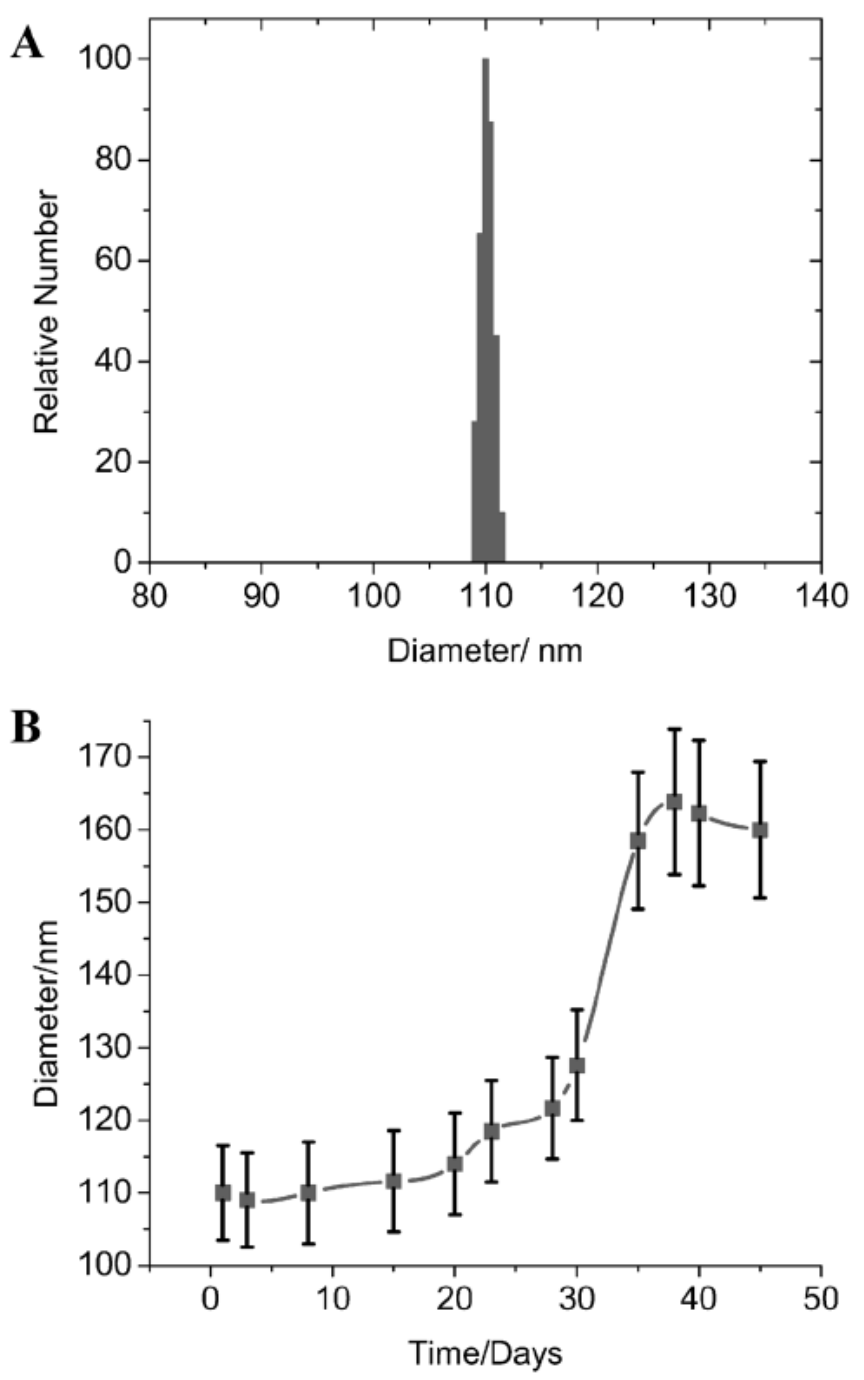

Fig. 1. A) Size distribution for suspended vesicles by dynamic light scattering. A homogeneous size is achieved by serial extru sions through polycarbonate filter membranes. Analysis of fresh ly prepared liposomes shows an average vesicle size of $110 \mathrm{~nm}$. The sample was monodisperse with a polydispersity index of less than 0.1. B) The liposome stability is illustrated as vesicles diam eter vs. the storage time at $4{ }^{\circ} \mathrm{C}$.

The total amount of NOS encapsulated in the liposomes was determined by the difference of NOS in liposome suspension and NOS inside the liposomes. To disperse liposomes, the vesicle suspension was treated with Triton X-100 (10\% w/v aqueous solution) at $37^{\circ} \mathrm{C}$. The vesicle/triton mixture was subjected to sonication in order to fully disrupt the liposomal membrane. After centrifugation, the supernatant is collected and analyzed for protein content quantification using the Bradford microassay. Table 1 shows Bradford assay results for batches of a typical NOS-liposome preparation. Overall, the encapsulation efficiency (\%) for NOS-loaded liposomes using the method described is found in $40 \pm 25 \%$ range. The loading capacity remains constant over the first 15 days at $4{ }^{\circ} \mathrm{C}$ storage. After this initial stability period, we observed a decrease in enzyme loading capacity, which mir- 
Table 1. Values obtained from Bradford assay. NOS*: input con centration after subtracting unloaded NOS.

\begin{tabular}{ll}
\hline Sample & [Enzyme] $(\mu \mathrm{g} / \mathrm{mL})$ \\
\hline NOS* & $8.0 \pm 2.3$ \\
Intact NOS loaded Liposome & $\sim 0.00$ \\
Disrupted NOS liposome & $3.0 \pm 2.1$ \\
\hline
\end{tabular}

rored the instability in terms of size as described in the previous section.

$\%$ NOS activity in liposomes. The Griess assay is commonly used to measure NO synthesis from NOS [20,21]. This assay quantifies the nitrite as the breakdown product of NO [22]. Appropriate controls with blanks containing all components except the NOS enzymes are part of the calibration curve construction process. The assay was used here to determine NOS activity in liposomes in comparison to NOS activity prior to encapsulation. The Griess assay measurements on our NOS-liposome preparations show that the percentage of the activity inside the liposomes is $\sim 76 \%(n=3)$ of the initial NOS activity. This relatively high \% activity value demonstrates the retaining of the NOS activity inside the vesicles.

Measurement of Nitric Oxide release from NOS in liposomes. We used our proprietary NO-sensitive electrochemical ruthenium-modified carbon microfiber sensor [23] in order to monitor nitric oxide dynamically released from single NOS-loaded liposomes upon NOS chemical stimulation. Details about the fabrication of the NOsensor are in the included in the experimental section. The NOS-loaded liposomes were incubated with a PBS buffer solution. A micromanipulator attached to the stage of an inverted microscope allowed the positioning of the NO-selective microsensor $10 \pm 1 \mu \mathrm{m}$ above the liposome surface. A potential of $+0.5 \mathrm{~V}$ vs. $\mathrm{Ag} / \mathrm{AgCl}$ was applied to the NO microsensor. Once a steady background current is obtained, an aliquot of $150 \mu \mathrm{M}$ of NADPH was injected $10 \pm 1 \mu \mathrm{m}$ away from the isolated single liposome surface to stimulate NO release. NO is then measured as an oxidation current on the NO-sensor.

A typical chronoamperometric dose-response curve in the form of a calibration plot for our NO-sensor is shown in Figure 2.

The amperometric response of the NO microsensor upon subsequent additions of NADPH and blank PBS buffer solution as a control to the NOS-loaded liposomes preparation is illustrated in Figure 3.

The stimulation of NO synthesis, upon injection of NADPH in the vicinity of a single liposome using micromanipulators on an inverted microscope stage, generated a flux of NO that is released and detected at the nearby NO-sensitive microfiber, in the form of a change in current signal as a function of time (Figure 3A). All electrochemical measurements are performed on fresh preparation of liposomes (1-2 days). The sharp drop in current signal after the injection of $45 \mathrm{nmol}$ of NADPH is due to the oxidation of the NO released from a single NOS-car-

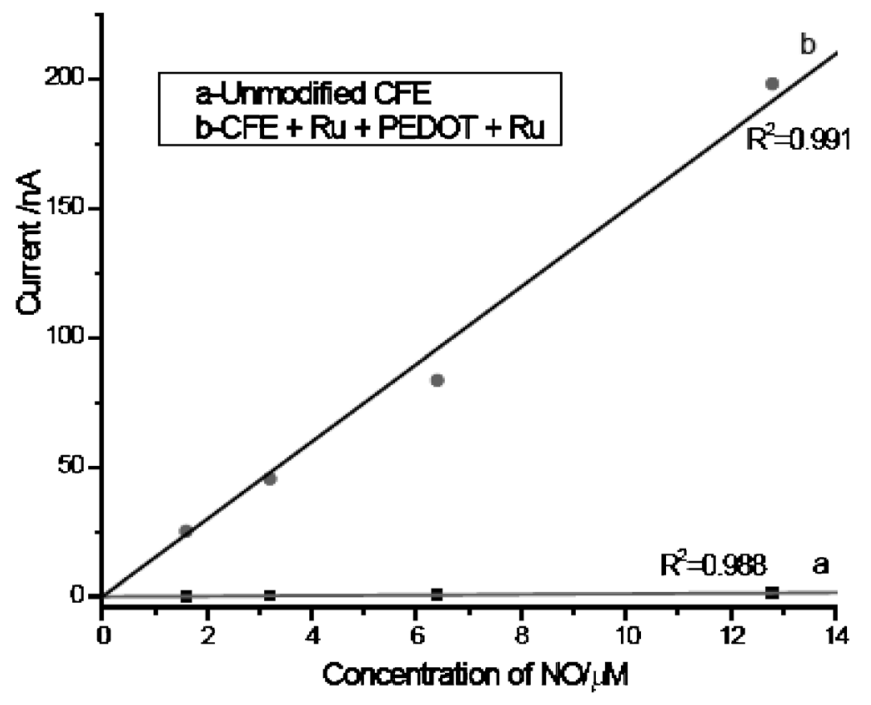

Fig. 2. Typical NO microsensor calibration plot.

rying liposome, isolated in a dilute liposome preparation. Control experiments with the addition of $10 \mu \mathrm{L}$ of buffer solution to NOS-liposomes did not give the response observed with NADPH. Also, as shown in Figure 3B, liposomes with NOS treated $\mathrm{L}-\mathrm{N}$-nitroarginine methyl ester (L-NAME), a known potent NOS-inhibitor, do not give the typical responses reflecting full activity. Also, injection of NADPH in the bulk of the solution did not yield the typical oxidation peaks observed when the microsensor is placed near NOS-carrying liposomes (Figure 3C).

The pulsed nitric oxide concentration profile released from each NOS-loaded liposome peaks at about $\sim 19.8 \mathrm{nM}$. Using a spherical diffusion model, we calculated the amount of NO released from one liposome to be around $\sim 3.7$ amol. This value remains relatively constant from one NOS-loaded liposome to another as long as the size does not change.

Conclusions. Overall, we show that NOS encapsulation in DSPC liposomes is achieved using the thin-film hydration method in the presence of NOS enzyme in the hydrating solution. A suspension of monodisperse NOS-containing vesicles is prepared using an extrusion process through a $100-\mathrm{nm}$ pore size membrane. Protein assay measurements show that the method as described achieves relatively high encapsulation efficiency of about $40 \pm 25 \%$. Size monitoring using DLS shows excellent stability of NOS-loaded liposomes during storage for at least 15 days, during which the NOS-enzymatic activity is also retained. Measurement of enzymatic activity shows that the percentage of the activity inside the liposomes is $-75 \%$ of the initial NOS activity. Electrochemical measurement of NO released from single NOS-loaded liposomes indicates that the amount of $\mathrm{NO}$ released from one liposome in the preparation as described is around $\sim 3.7$ amol. Together, these results show that NOS encapsulation in DSPC liposomes is a viable approach for the delivery of active NOS enzymes to targeted sites. Work is now in progress to investigate the use and efficiency of 

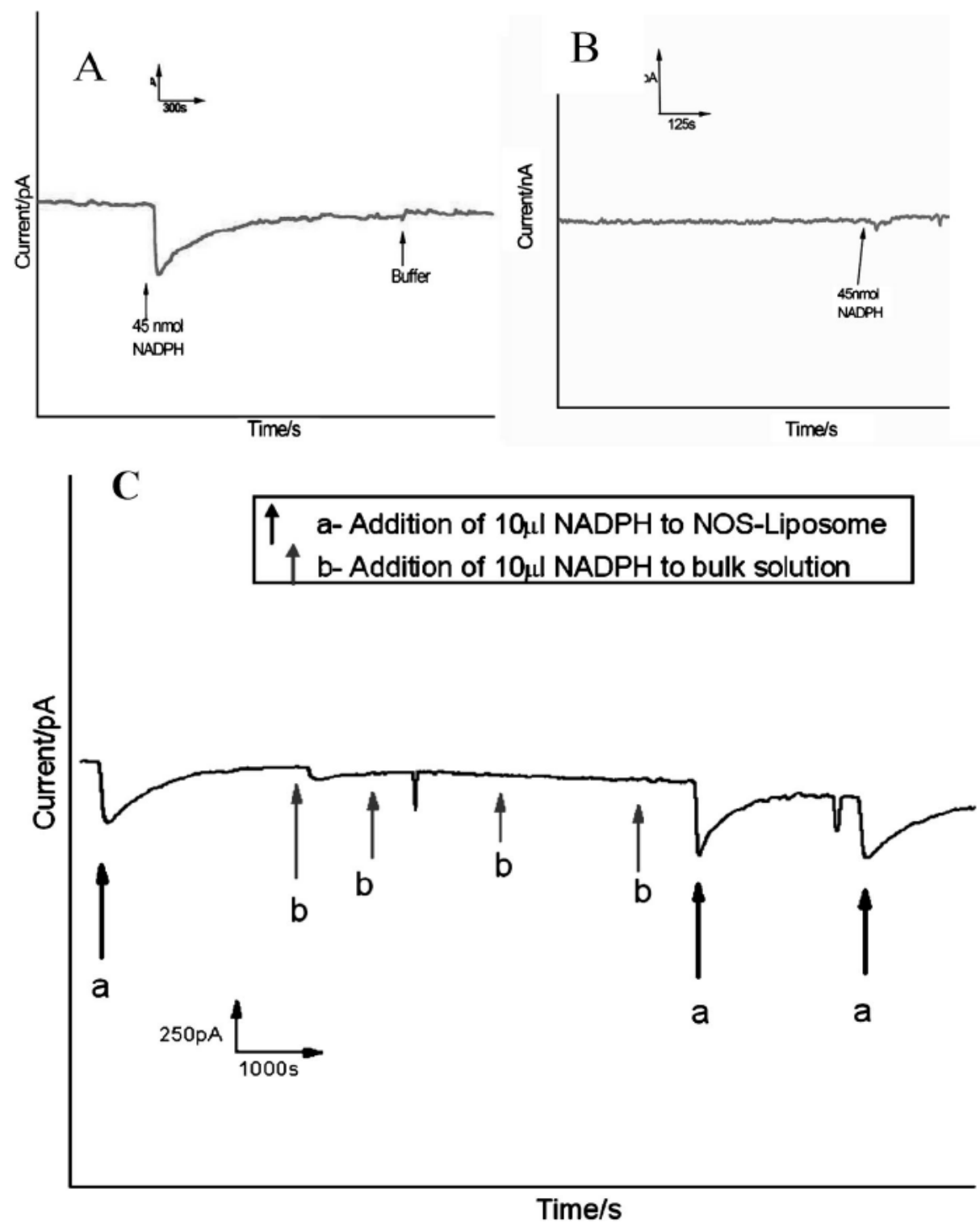

Fig. 3. A) Amperometric response of the NO microsensor upon the subsequent addition of NADPH and PBS buffer solution to the NOS carrying liposome; B) Response of the same NO microsensor upon NADPH addition to the NOS carrying liposome after treat ment with the NOS inhibitor L NAME; C) Response of same NO microsensor upon the NADPH injection both near NOS carrying liposomes (arrows "a") and in the bulk solution away from NOS carrying liposomes (arrows "b").

NOS-carrying liposomes as potential delivery vehicles of active NOS enzymes to NO-deficient live cell as target models.

\section{Experimental}

The 1,2-distearoyl-glycero-3-phosphocholine (DSPC) was obtained from Avanti Polar Lipids (Alabaster, $\mathrm{Al}$ ). The cholesterol, Trizma base, $\mathrm{K}_{3} \mathrm{PO}_{4}, \mathrm{KH}_{2} \mathrm{PO}_{4}, \mathrm{MgSO}_{4}$, EDTA, Triton-X, and glycerol were purchased from Sigma-Aldrich (St Louis, MO). The nanopure deionized water from by a Barnstead water purification system model D8961 had a specific resistance $>18.2 \mathrm{M} \Omega \mathrm{cm}$ and was used throughout. All chemicals were reagent grade and were utilized as received. The Bradford assay kit was obtained from Bio-Rad Laboratories (Hercules, CA) and the Griess reagent kit was purchased from Promega (Madison, WI). The electrochemical monitoring was performed on a CHI-440 workstation (CH Instruments, Inc., Austin, TX) or the Apollo system (WPI, Sarasota, FL).

Liposomes were obtained by the thin-film hydration method followed by an extrusion process through a $100 \mathrm{~nm}$ pore size membrane [24]. The lipid film was allowed to swell overnight at $4{ }^{\circ} \mathrm{C}$. Finally, the sample was subjected to 10 freeze thaw cycles in liquid nitrogen and warm water. The unilamellar vesicles were then extruded through $0.1 \mu \mathrm{m}(100 \mathrm{~nm})$ pore-size polycarbonate filters, to obtain uniform-size liposomes. The suspension of vesicles was then stored at $4^{\circ} \mathrm{C}$ for several days. 
The recombinant iNOS proteins used in this work were overexpressed in the E. coli strain BL21 (DE3) using a pCWori vector and purified as reported in the literature [25]. The plasmid was a kind gift from Dr. Stuehr's labs (Lerner Research Institute, Cleveland Clinic).

The dry, thin, lipid film was further dried, by flowing dry $\mathrm{N}_{2}$ gas into the flask and ensure complete evaporation of the organic solvent. An aqueous solution of the iNOS enzyme of $0.45 \mu \mathrm{M}$ concentration was then used to hydrate the lipid film before dilution with a $\mathrm{pH} 7.4$ buffer solution. In order to eliminate non-encapsulated protein, the liposome suspension was passed through a $\mathrm{Ni}^{2+}$ column, which traps only the free histidine-tagged iNOS proteins. The fractions containing NOS-carrying liposomes were collected and used for further analysis.

The liposome average diameter and size distribution of the vesicles were determined by the dynamic light scattering (DLS). A $20 \mu \mathrm{L}$ aliquot of the liposome dispersion was diluted with $1 \mathrm{ml}$ of filtered buffer solution $(0.2 \mu \mathrm{m}$ pore size polycarbonate filters) and measurements were made at $25^{\circ} \mathrm{C}$. The stability of the liposome dispersion upon storage at $4{ }^{\circ} \mathrm{C}$ was monitored periodically by DLS.

The Griess assay reagent kit was used with the instruction provided. Briefly, the NADPH-treated $100 \mu \mathrm{L}$ of sample was incubated with $100 \mu \mathrm{L}$ of sulfanilamide for 10 minutes in the dark followed by 10 -minute reaction with $100 \mu \mathrm{L} N$-1-napthylethylenediamine dihydrochloride (NAD) in the dark at room temperature. The absorbance was recorded at $540 \mathrm{~nm}$. A calibration curve was constructed using known concentration series of $\mathrm{NO}$ in buffer conditions similar to our liposomal preparations.

The enzyme activity of NOS-carrying liposomes was determined via the detection of NO, released when stimulated by NADPH, with our Ru-PEDOT modified carbon fiber electrode (CFE) NO-sensitive microsensor. All electrochemical measurement of NO synthesis from NOScarying liposomes is performed on freshly prepared NOSliposomes (1-2 days). Experimental details about the NO-sensor are found elsewhere [23] as well as in other reports about other CFE microsensors developed in our labs [26]. Briefly, this NO microsensor was fabricated as follows. A single carbon fiber $(7 \mu \mathrm{m}$ diameter $)$ was mounted on the end of a copper wire using conductive epoxy, then inserted into the glass capillary and sealed. The carbon fiber was cut leaving a protruding portion of about to $3 \mathrm{~mm}$. All potentials reported here are versus a $\mathrm{Ag} / \mathrm{AgCl}$ reference electrode. A platinum wire was used as the auxiliary electrode. The polymerization of 3,4-ethylenedioxythiophene (EDOT) monomer was done in a three-electrode electrochemical cell, to provide the matrix on which the catalytic ruthenium nanoparticles used in NO sensing are deposited. The ruthenium nanoparticles are then deposited from a $\mathrm{RuCl}_{3}$ solution in perchloric acid.

\section{Acknowledgements}

This research was supported by the National Science Foundation (MB; Grant CHE-0848820) and by an FRD and seed grants from CSU-Ohio Board of Regents. We wish to acknowledge Xue-Long Sun Lab for access to a DLS. SFP acknowledges initial support by a J. William Fulbright Senior Grant in Biological Sciences from C. I. E.S.

\section{References}

[1] R. M. Palmer, A. G. Ferrige, S. Moncada, Nature 1987, 327, 524 .

[2] C. Nathan, Faseb. J. 1992, 6, 3051.

[3] C. Moncada, D. Lekieffre, B. Arvin, B. Meldrum, Neurore port 1992, 3, 530 .

[4] M. N. Friedemann, S. W. Robinson, G. A. Gerhardt, Anal. Chem. 1996, 68, 2621.

[5] H. Jaeschke, V. B. Schini, A. Farhood, Life Sci. 1992, 50, 1797.

[6] T. M. Dawson, V. L. Dawson, S. H. Snyder, Annals Neurol. 1992, 32, 297.

[7] K. S. Manchester, F. E. Jensen, S. Warach, S. A. Lipton, Neurology 1993, 43, A365.

[8] S. A. Lipton, Y. B. Choi, Z. H. Pan, S. Z. Z. Lei, H. S. V. Chen, N. J. Sucher, J. Loscalzo, D. J. Singel, J. S. Stamler, Nature 1993, 364, 626.

[9] D. J. Stuehr, C. C. Wei, Z. Wang, R. Hille, Dalton Trans. 2005, 3427.

[10] R. A. Johnson, R. H. Freeman, Am. J. Hypertens. 1992, 5, 919.

[11] V. Lahera, J. Salazar, M. G. Salom, J. C. Romero, J. Hyper tens. Suppl. 1992, 10, S173.

[12] G. Brock, L. Nunes, H. Padma Nathan, S. Boyd, T. F. Lue, Urology 1993, 42, 412.

[13] E. McGuffey, Am. Pharm. 1993, NS33, 20.

[14] J. Koglin, T. Glysing Jensen, J. S. Mudgett, M. E. Russell, Circulation 1998, 97, 2059.

[15] M. Weis, T. N. Kledal, K. Y. Lin, S. N. Panchal, S. Z. Gao, H. A. Valantine, E. S. Mocarski, J. P. Cooke, Circulation 2004, 109, 500 .

[16] A. F. Chen, J. Ren, C. Y. Miao, Jpn. J. Pharmacol. 2002, 89, 327.

[17] K. M. Channon, M. A. Blazing, G. A. Shetty, K. E. Potts, S. E. George, Cardiovascular Res. 1996, 32, 962.

[18] K. Yamasaki, H. D. Edington, C. McClosky, E. Tzeng, A. Lizonova, I. Kovesdi, D. L. Steed, T. R. Billiar, J. Clin. Invest. 1998, 101, 967.

[19] N. Kaiser, A. Kimpfler, U. Massing, A. M. Burger, H. H. Fiebig, M. Brandl, R. Schubert, Int. J. Pharm. 2003, 256, 123.

[20] T. S. Maurer and H. L. Fung, Nitric Oxide 2000, 4, 372.

[21] S. Pfeiffer, A. C. Gorren, K. Schmidt, E. R. Werner, B. Han sert, D. S. Bohle, B. Mayer, J Biol. Chem. 1997, 272, 3465.

[22] D. Tsikas, Anal. Chem. 2000, 72, 4064.

[23] M. Bayachou, P. Peiris, USA Patent No. 7,914,664, 2011.

[24] K. Kono, R. Nakai, K. Morimoto, T. Takagishi, Biochim. Biophys. Acta 1999, 1416, 239.

[25] D. K. Ghosh, C. Wu, E. Pitters, M. Moloney, E. R. Werner, B. Mayer, D. J. Stuehr, Biochemistry 1997, 36, 10609.

[26] S. F. Peteu, P. Peiris, E. Gebremichael, M. Bayachou, Bio sens. Bioelectron. 2010, 25, 1914. 